\title{
Trends in Dietary Intakes and Serum Cholesterol Levels over 50 Years in Tanushimaru in Japanese Men
}

\author{
Hisashi Adachi ${ }^{*}$, Yuji Hirai ${ }^{2}$, Satoshi Sasaki ${ }^{3}$, Mika Enomoto $^{2}$, Ako Fukami ${ }^{2}$, Eita Kumagai ${ }^{2}$, Eishi \\ Esaki $^{2}$, Tsutomu Imaizumi ${ }^{2}$
}

${ }^{1}$ Department of Community Medicine, Kurume University School of Medicine, Kurume, Japan; ${ }^{2}$ Department of Internal Medicine, Division of Cardio-Vascular Medicine, Kurume University School of Medicine, Kurume, Japan; ${ }^{3}$ Department of Social and Preventive Epidemiology School of Health, The University of Tokyo, Tokyo, Japan.

Email: "hadac@med.kurume-u.ac.jp

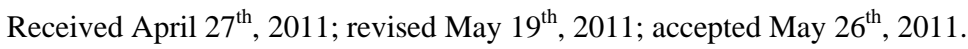

\begin{abstract}
We investigated the relationship between time trends in dietary intakes and serum cholesterol levels in a Japanese cohort of the Seven Countries Study, in Tanushimaru, a typical farming town on Kyushu Island. Total subjects were 628 in 1958, 539 in 1977, 602 in 1982, 752 in 1989, 402 in 1999, and 329 in 2009, and all of the subjects were men aged 40 64 years. Eating patterns were evaluated by 24-hour dietary recall from 1958 through 1989, and by a food frequency questionnaire in 1999 and 2009. We also measured serum cholesterol levels in each health examination. The total energy intake decreased from 2,837 kcal in 1958 to 2,289 kcal in 2009. The carbohydrate intake in percentage of total energy intake decreased markedly, from 84\% in 1958 to 58\% in 2009, in contrast to large increases during this period in protein intake (from $11 \%$ to $16 \%$ ) and fat intake (from $5 \%$ to $22 \%$ ). In proportion to the dramatic change in protein and fat intake, serum cholesterol levels showed large increases (from $152.5 \mathrm{mg} / \mathrm{dl}$ to $207.7 \mathrm{mg} / \mathrm{dl}$ ). Despite of such big dietary changes toward a westernized diet, incidence of coronary heart disease has not increased in our cohort for a couple of decades. However, careful surveillance is needed in the future because of the remarkably increasing intake of fats.
\end{abstract}

Keywords: Epidemiology, Diet, Risk Factor, Cardiovascular Disease

\section{Introduction}

At the beginning of the Seven Countries Study in 1958, data of Tanushimaru of a Japanese cohort presented with the lowest saturated fat intake and serum cholesterol levels, and with the lowest rates of coronary heart disease [1]. Subsequently, Japan has experienced dramatic changes in lifestyle and eating patterns associated with socioeconomic development [2]. We have reported results of a trend in nutritional intake and serum cholesterol levels up to 1989 [3]. In this report [3], changes in eating patterns have probably contributed to the progressive increases in average serum cholesterol levels.

We recently carried out a physical examination in the same district of Tanushimaru town in 2009. The aim of the present study is to describe time trends in eating patterns and serum cholesterol levels including recent data, and to discuss how these transitions will influence the future incidence of coronary heart disease.

\section{Subjects and Methods}

\subsection{Subjects}

Trends in dietary patterns and serum cholesterol levels have been monitored in a typical farming town, Tanushimaru, located in Kyushu, the southwestern island of Japan. The first survey of a Japanese cohort of the Seven Countries Study was conducted in 1958 [1]. All men $(n=$ 628) aged 40 - 64 years who were born and had lived in the Chikugo area of Tanushimaru were enrolled, with a response rate of $100 \%$. In 1977, an independent second cohort was identified; enrolling 573 men aged 40-64 years in the same district of Tanushimaru. This newly drawn cross-sectional survey (response rate 97.1\%) included some who participated in the first survey in 1958. The third cross-sectional survey (response rate $77.0 \%$ ) in 
1982 of 602 men aged 40 - 64 years, and the fourth cross-sectional survey (response rate 89.0\%) in 1989 of 752 men aged 40 - 64 years were also conducted. The fifth examination (response rate 48.2\%) was carried out in 1999 in the same district on 402 men, and the latest examination (response rate 39.0\%) was carried out in 2009 on 329 men.

\subsection{Data Collection}

Each cross-sectional survey was conducted using the common protocol described in detail by Keys and associates $[1,4]$. Although the standard cohorts of the Seven Countries Study were men aged 40 - 59, men aged 60 64 years were also included. The recorded data included 1) age; 2) occupation; 3) eating patterns 4) alcohol consumption and smoking habits; 5) body mass index; 6) physical activity; 7) blood pressure; and 8) serum cholesterol. Eating patterns were evaluated by 24-hour dietary recall [5] in 1958, 1977, 1982, and 1989, and by a 105 item food frequency questionnaire modified by the use of ARIC study dietary intake form [6,7] in 1999. Eating pattern was evaluated by brief-type self-administered diet history questionnaire: BDHQ in the latest examination $[8,9]$. Each evaluation by 24-hour dietary recall from 1958 to 1989, by ARIC study dietary intake form in 1999, and by BDHQ dietary intake form in 2009 was performed by standard tables of food composition in Japan, 4th revision [10].

Serum cholesterol was measured by the Anderson-Keys method [11] using a modification of the method of Abel et al. [12] in 1958 and measured by the enzymatic method of Allain et al. [13] in 1977, 1982, 1989, 1999 and 2009. To standardize cholesterol levels, the samples of blood serum cholesterol were frozen and sent by air to Minneapolis laboratory at the University of Minnesota in the first survey. Although new methods were added in the second to sixth surveys, the same protocol was followed. The standardized serum cholesterol levels were measured at a commercially available laboratory (BML Inc., Japan). Control surveys of serum cholesterol were performed in the same laboratory.

This study was approved by the Japan Medical Association of Ukiha (Tanushimaru) branch, by a mayor, and by the welfare section of the Tanushimaru town office. All participants in 1989, 1999, and 2009 received oral and written explanations of the study as an informed consent. In the recent physical examination in 1999 and 2009, the Ethics Committee of Kurume University School of Medicine also approved this study.

\subsection{Statistical Methods}

Results are presented as mean values or percentages in 1958, 1977, 1982, 1989, 1999, and 2009. All statistical analyses were performed with the use of the SAS system [14].

\section{Results}

Time trends in study subjects and response rate were shown in Table 1. The response rate is much lower in the later surveys. The sample size became small, and the number of subjects who were resurveyed was also getting small.

The serial changes in dietary intakes in Tanushimaru are summarized in Table 2. In 1958, the total energy intake was 2,837 kcal, and $84 \%$ was derived from carbohydrates. Total energy intake decreased to 2,289 kcal in 2009. However, there was a progressive decrease in intake of carbohydrates, from $84 \%$ in 1958 to $58 \%$ in 2009 , and a progressive increase in intake of fat, from $5 \%$ to $22 \%$, and protein, from $11 \%$ to $16 \%$.

These changes in food intake are presented in Table 3. Rice intake decreased dramatically, from 593 g/day in 1958 to 299 g/day in 1977 and 290 g/day in 1982, and then fell to 232 g/day in 1989, to 236 g/day in 1999, and to $226 \mathrm{~g}$ /day in 2009 . There have been progressive increases in intake of meats, from $13 \mathrm{~g} /$ day in 1958 to 92 g/day in 1999, and in intake of milk, from 13g/day in 1958 to $97 \mathrm{~g} /$ day in 2009. Intake of fish and shellfish rose from $56 \mathrm{~g} /$ day in 1958 to $95 \mathrm{~g} /$ day in 1977, remained stable thereafter, then fell to $71 \mathrm{~g}$ /day in 1999, and again rose to $95 \mathrm{~g}$ /day in 2009.

The average serum cholesterol levels are shown in

Table 1. Time trends in study subjects and response rate.

\begin{tabular}{lllllll}
\hline & 1958 & 1977 & 1982 & 1989 & 1999 & 2009 \\
\hline Males & 639 & 573 & 602 & 752 & 405 & 329 \\
Response rate & 100 & 91 & 77 & 89 & 48 & 39 \\
Females & - & - & 747 & 707 & 627 & 536 \\
Response rate & - & - & 81 & 70 & 62 & 53 \\
\hline
\end{tabular}

Age 40 - 64 years.

Table 2. Time trend in total energy intake and percent energy intake from fat, carbohydrate, and protein.

\begin{tabular}{lllllll}
\hline & 1958 & 1977 & 1982 & 1989 & 1999 & 2009 \\
\hline Energy (kcal) & 2,837 & 2,243 & 2,215 & 2,205 & 2,202 & 2,289 \\
Protein (\%) & 11 & 13 & 13 & 16 & 18 & 16 \\
Fat (\%) & 5 & 13 & 15 & 22 & 20 & 22 \\
Carbohydrates (\%) & 84 & 74 & 72 & 62 & 62 & 58 \\
\hline
\end{tabular}

Results are presented as mean values or percentages.

Table 3. Time trends in food intake (g/day).

\begin{tabular}{lllllll}
\hline & 1958 & 1977 & 1982 & 1989 & 1999 & 2009 \\
\hline Rice & 539 & 290 & 290 & 232 & 236 & 226 \\
Meats & 13 & 31 & 45 & 74 & 92 & 90 \\
Fish and shellfish & 56 & 95 & 97 & 105 & 71 & 95 \\
Milk & 13 & 31 & 45 & 74 & 99 & 97 \\
\hline
\end{tabular}

Results are presented as mean values. 
Table 4. The levels in men progressively increase from $152.5 \mathrm{mg} / \mathrm{dl}$ in 1958 to $189.7 \mathrm{mg} / \mathrm{dl}$ in 1989 , to 194.2 $\mathrm{mg} / \mathrm{dl}$ in 1999, and to $207.7 \mathrm{mg} / \mathrm{dl}$ in 2009. The serial changes of average systolic and diastolic blood pressures (BPs), percentage of hypertensive medication, body mass index (BMI), uric acid, and percentage of smokers are also shown. Gradual increases in diastolic BP, percentage of hypertensive medication, BMI, and uric acid as well as gradual decreases in percentage of smokers are evident.

\section{Discussions}

Large changes in dietary patterns and remarkable changes in serum cholesterol levels among men in Japanese farming areas aged 40 - 64 years were demonstrated [15]. Although a relationship between coronary risk factors and dietary changes was reported in the Cretan population in the Seven Countries Study [16], there are few epidemiologic studies that have been conducted in large cities because long-term follow-up is difficult in mobile urban populations.

The reduction of total energy intake can be attributed in part to the dramatic changes in working conditions of farming Japan, from traditional heavy physical labor to the current use of automated farming machines. Reduced walking due to the wider use of automobiles may be an additional factor. It could be indicated by a gradual increase in BMI. Departure from the traditional Japanese diet, high in salt and carbohydrate while low in fat and protein, toward a Westernized diet and eating patterns, has further contributed to these major trends. As shown in Table 2, intakes of meat and milk have been increasing. They may be strongly associated with increases of fat and protein. Like our study, the Japan National Nutrition Survey showed a progressively higher fat intake,

Table 4. Time trends in coronary risk factors.

\begin{tabular}{|c|c|c|c|c|c|c|}
\hline & 1958 & 1977 & 1982 & 1989 & 1999 & 2009 \\
\hline $\begin{array}{l}\text { Total cholesterol } \\
\text { (mg/dL) }\end{array}$ & 152.5 & 160.9 & 177.5 & 189.7 & 194.2 & 207.7 \\
\hline $\begin{array}{l}\text { Systolic BP } \\
\text { (mmHg) }\end{array}$ & 132.9 & 128.8 & 133.2 & 131.0 & 131.6 & 132.0 \\
\hline $\begin{array}{l}\text { Diastolic BP } \\
(\mathrm{mmHg})\end{array}$ & 73.5 & 76.3 & 81.6 & 79.7 & 82.0 & 86.2 \\
\hline $\begin{array}{l}\text { Hypertensive me- } \\
\text { dication (\%) }\end{array}$ & 3 & 4 & 5 & 7 & 20 & 33 \\
\hline $\begin{array}{l}\text { Body mass } \\
\text { index }\left(\mathrm{kg} / \mathrm{m}^{2}\right)\end{array}$ & 21.7 & 22.7 & 23.0 & 23.3 & 23.7 & 24.1 \\
\hline Uric acid (mg/dL) & - & 5.2 & 5.3 & 5.8 & 5.9 & 6.1 \\
\hline $\begin{array}{l}\text { Smoking } \\
\text { rate (\%) }\end{array}$ & 68.5 & 68.9 & 62.0 & 57.5 & 45.2 & 37.6 \\
\hline
\end{tabular}

Results are presented as mean values or percentages. Abbreviations: BP: Blood pressure. reaching $25 \%$ of the total energy by 1988 [17]. A separate northern Japan study performed in Akita [18], which was also conducted in a farming community, did not contradict these results.

With economic development, Japanese urban populations are tending toward westernized lifestyles and eating patterns. It is thus quite possible that their intake, particularly of animal fat, is considerably higher, leading to much higher average cholesterol levels. In the Tanushimaru cohort, the latest serum cholesterol level was around $208 \mathrm{mg} / \mathrm{dl}$. However, the examinations were conducted in a rural farming community. It seems that serum cholesterol levels in this rural study are a little different from those in urban areas [19]. In fact, recent statistics from the Ministry of Health and Welfare [20] have reported higher serum cholesterol levels than the Tanushimaru study, in both men and women.

It has been noted that the incidence of coronary heart disease has not increased in this cohort for a couple of decades (data not shown) [15,21]. Konishi et al. [22] have monitored the incidence of cardiovascular disease in desk workers of several large companies in Osaka (the second biggest city in Japan) since 1965 . They found a considerable decrease in the incidence of stroke. They also noted an increasing trend of coronary heart disease, although this trend was not statistically significant. The Hisayama study, which has been conducted in the same area of Kyushu, also showed the same trend [23].

On the other hand, the incidence of coronary heart disease in America is much higher than in Japan, although it has been gradually decreasing [24,25]. The upward trend of coronary heart disease in Osaka could not be explained solely by higher cholesterol levels, so other risk factors were considered, such as stress, smoking, and decreased physical exercise. However, excluding obesity [26], the Japanese subjects tested displayed higher prevalence of hypertension [27], rate of smoking [28], and levels of stress [29], and lower levels of physical activity than their American counterparts [30]. Moreover, it is reported that recent cholesterol levels in Japanese men showed almost the same levels as those of American men [19,24,31]. In this study, large increase (from $152.5 \mathrm{mg} / \mathrm{dl}$ to $207.7 \mathrm{mg} / \mathrm{dl}$ ) in serum cholesterol levels and gradual increases in BMI (from $21.7 \mathrm{~kg} / \mathrm{m}^{2}$ to $24.1 \mathrm{~kg} / \mathrm{m}^{2}$ ), in diastolic BP (from $73.5 \mathrm{~mm} \mathrm{Hg}$ to 86.2 $\mathrm{mm} \mathrm{Hg}$ ) and in uric acid (from $5.2 \mathrm{mg} / \mathrm{dl}$ to $6.1 \mathrm{mg} / \mathrm{dl}$ ) were found. The majority of the change in eating behavior occurred between 1958 and 1977 while the biomarkers changed later. Nevertheless, it is true that Japanese are now enjoying the greatest longevity in the world, and fewer people suffer from coronary heart disease.

This paradox may be interpreted by the comparisons of $\mathrm{P} / \mathrm{S}$ (= polyunsaturated/saturated fat) ratios between 
U.S. and Japan. People in Western countries consume more saturated fat and less polyunsaturated fat than Japanese [11,32]; thus P/S ratio was about 1.0 in this district whereas it is much lower in Western countries [33,34].

The present study has several limitations. First, the response rate is much lower in the later surveys. An analysis of those who refused the later studies may indicate a systematic bias. The second limitation is the different methodology of dietary assessment. The dietary intake was evaluated by 24-hour dietary recall in 1958, 1977, 1982, and 1989. However, it was evaluated by food frequency questionnaires in 1999 and 2009. Although the data obtained from the modified ARIC Study's Food Frequency Questionnaire [7] used in 1999 was similar to the results of The National Nutrition Survey in Japan, there is no other data on the validity such as reproducibility [35]. A reasonable validity and reproducibility was reported for BDHQ used in 2009 [8,9]. The dietary data used for validation was compared with the results of The National Nutrition Survey in 1999 [35,36]. Total energy intake in this district was 2,289 kcal (versus 2,301 kcal in the results of The National Nutrition Survey in 1999), the percentage of carbohydrate intake of total calories was $58 \%$ (versus $59 \%$ ), protein intake was $16 \%$ (versus $16 \%$ ), and fat intake was $22 \%$ (versus $24 \%$ ). Thus, the eating pattern in this district examined by the BDHQ [8,9] was similar to that of The National Nutrition Survey in Japan.

In conclusion, large changes in dietary patterns and remarkable changes in serum cholesterol levels among men aged 40 - 64 years in a Japanese farming area were demonstrated. Fortunately, incidence of coronary heart disease has not increased in our cohort for a couple of decades. The varied composition of the Japanese diet has probably prevented coronary heart disease. However, careful surveillance is needed in the future because of the increasing intake of fat, especially saturated fatty acids, with the potential of a modern epidemic of coronary heart disease in Japan.

\section{Acknowledgements}

We are grateful to members of the Japan Medical Association of Ukiha, the elected officials and residents of Tanushimaru, and the team of physicians for their help in carrying out the health examinations.

\section{REFERENCES}

[1] A. Keys, C. Aravanis, H. Blackburn, R. Buzina, B. S. Djordjevic, A. S. Dontas, F. Fidanza, M. J. Karvonen, N. Kimura, A. Menotti, I. Mohachek, S. Nedeljkovic, V. Puddu, S. Punsar, H. L. Taylor and F. S. P. Van Buchem, "Seven Countries Study: A Multivaliate Analysis of Death and Coronary Artery Disease,” Harvard University Press, Cambridge, 1980.
[2] H. Toshima, H. Tashiro, M. Sumie, Y. Koga and N. Kimura, "Nutritional Prevention of Cardiovascular Disease,” In: W. Lovenberg and Y. Yamori, Eds., Changes in risk factors and cardiovascular mortality and morbidity within Tanushimaru 1958-1982, Academic Press, New York, 1984, pp. 203-210.

[3] Y. Koga, R. Hashimoto, H. Adachi, M. Tsuruta, H. Tashiro and H. Toshima, "Recent Trends in Cardiovascular Disease and Risk Factors in the Seven Countries Study," In: H. Toshima, Y. Koga, H. Blackburn and A. Keys, Eds., Lessons for Science from the Seven Countries Study: A 35-Year Collaborative Experience in Cardiovascular Disease Epidemiology, Springer-Verlag, Tokyo, 1994, pp. 63-74.

[4] A. Keys, H. Blackburn, F. S. P. Van Buchem, R. Buzina, B. S. Djordjevic, A. S. Dontas, F. Fidanza, M. J. Karvonen, N. Kimura, D. Lekos, M. Monti, V. Puddu and H. L. Taylor, "Epidemiological Studies Related to Coronary Heart Disease: Characteristics Men Aged 40-59 in Seven Countries," Acta Medica Scandinavica, Vol. 460, 1966, pp. 1-392.

[5] I. F. Hunt, L. S. Luke, N. J. Murphy, V. A. Clark and A. H. Coulson, "Nutrient Estimates for Computerized Questionnaire vs. 24-hr. Recall Interviews," Journal of the American Dietetic Association, Vol. 74, No. 6, 1979, pp. 656-659.

[6] F. E. Thompson and T. Byers, "Dietary Assessment Resource Manual,” The Journal of Nutrition, Vol. 11, 1994, pp. 2245S-2317S.

[7] The ARIC Investigators, "The Atherosclerosis Risk in Communities (ARIC) Study: Design and Objectives," American Journal of Epidemiology, Vol. 129, No. 4, 1989, pp. 687-702.

[8] S. Sasaki, "Development and Evaluation of Dietary Assessment Methods Using Biomarkers and Diet History Questionnaires for Individuals,” In: H. Tanaka, Ed., Research for Evaluation Methods of Nutrition and Dietary Lifestyle Programs Held on Healthy Japan 21, Summary Report, Ministry of Health, Welfare, and Labour, Tokyo, 2004, pp. 10-44 (in Japanese).

[9] S. Kobayashi, K. Murakami, S. Sasaki, H. Okubo, N. Hirota, A. Notsu, M. Fukui and C. Date, "Comparison of Relative Validity of Food Group Intakes Estimated by Comprehensive and Brief-Type Self-Administered Diet History Questionnaires against 16 d Dietary Records in JAPANESE Adults," Public Health Nutrition, Vol. 11, No. 4, 2011, pp. 1-12.

[10] "Standard Tables of Food Composition in Japan," 4th Revision Edition, Resource Council Science and Technology Agency, Printing bureau, Ministry of Finance, Japan, 1999 (in Japanese).

[11] J. T. Anderson and A. Keys, "Cholesterol in Serum Lipoprotein Fractions: Its Measurement and Stability,” Clinical Chemistry, Vol. 2, No. 3, 1956, pp. 145-159.

[12] L. L. Abel, B. B. Levy, B. B. Brodie and F. E. Kendall, "A Simplified Method for the Estimation of Total Cholesterol in Serum and Demonstration of Its Specificity," 
The Journal of Biological Chemistry, Vol. 195, No. 1, 1952, pp. 357-366.

[13] C. C. Allain, L. S. Poon, C. S. Chan, W. Richmond and P. C. Fu, "Enzymatic Determination of Total Serum Cholesterol," Clinical Chemistry, Vol. 20, No. 4, 1974, pp. 470-475.

[14] SAS Institute, SAS/STAT Software: Changes and enhancements through release 9.2, SAS Institute, Inc., Cary, NC, 2007.

[15] H. Adachi and A. Hino, "Trends in Nutritional Intake and Serum Cholesterol Levels over 40 Years in Tanushimaru, Japanese Men,” Journal of Epidemiology, Vol. 15, No. 3, 2005, pp. 85-89. doi:10.2188/jea.15.85

[16] A. Kafatos, A. Diacatou, G. Voukiklaris, N. Nikolakakis, J. Vlachonikolis, D. Kounali, G. Mamalakis and A. S. Dontas, "Heart Disease Risk-Factor Status and Dietary Changes in the Cretan Population over the Past 30y: The Seven Countries Study," The American Journal of Clinical Nutrition, Vol. 65, No. 6, 1997, pp.1882-1886.

[17] J. Matsuura, M. Siina and S. Hattori, "Trends in Nutritional Intake in Japanese," Journal of Health and Walfare Statistics (Kosei no Shihyo), Vol. 39, 1992, pp. 93-95 (in Japanese).

[18] T. Shimamoto, Y. Komachi, H. Inada, M. Doi, H. Iso, S. Sato, A. Kitamura, M. Iida, M. Konishi and N. Nakanishi, "Trend for Coronary Heart Disease and Stroke and Their Risk Factors in Japan,” Circulation, Vol. 79, No. 3, 1989, pp. 503-515. doi:10.1161/01.CIR.79.3.503

[19] A. Okayama, H. Ueshima, M. G. Marmot, P. Elliott, M. Yamakawa and Y. Kita, "Different Trends in Serum Cholesterol Levels among Rural and Urban Populations Aged 40-59 in Japan from 1960 to 1990," Journal of Clinical Epidemiology, Vol. 48, No. 3, 1995, pp. 329-337. doi:10.1016/0895-4356(94)00146-H

[20] Ministry of Health and Welfare, "National Survey on Circulatory Disorders, 1990,” Japan Cardiovascular Research Foundation, Osaka, 1993.

[21] H. Toshima, “Coronary Artery Disease in Japan,” Japanese Circulation Journal, Vol. 58, No. 3, 1994, pp.166172. doi:10.1253/jcj.58.166

[22] M. Konishi, M. Iida and Y. Naito, "Studies on the Relationship between the Trend of Serum Cholesterol Level and the Increase of Cerebro Cardiovascular Diseases Based on the Follow-up Studies in Akita and Osaka with a Special Reference to the Optimal Serum Total Cholesterol Level Preventing Both Cerebral Hemorrhage and Coronary Heart Disease," Japanese Atherosclerotic Society, Vol. 25, 1987, pp. 1115-1123 (in Japanese).

[23] Y. Tanizaki, Y. Kiyohara, I. Kato, H. Iwamoto, K. Nakayama, N. Shinohara, H. Arima, K. Tanaka, S. Ibayashi and M. Fujishima, "Incidence and Risk Factors for Subtypes of Cerebral Infarction in a General Population: The Hisayama Study," Stroke, Vol. 31, No. 11, 2000, pp. 2612-2622. doi:10.1161/01.STR.31.11.2616

[24] C. L. Johnson, B. M. Rifkind, C. T. Sempos, M. D. Carroll, P. S. Bachorik, R. R. Briefel, D. J. Gordon, V. L. Burt, C. D. Brown and K. Lippel, "Declining Serum Total
Cholesterol Levels among US Adults. The National Health and Nutritional Surveys," The Journal of the American Medical Association, Vol. 269, No. 23, 1993, pp. 3002-3008. doi:10.1001/jama.269.23.3002

[25] A. Sekikawa, L. H. Kuller, H. Ueshima, J. E. Park, I. Suh, S. H. Jee, H. K. Lee and W. H. Pan, "Coronary Heart Disease Mortality Trends in Men in the Post World War II Birth Cohorts Aged 35-44 in Japan, Korea and Taiwan compared with the United States,” International Journal of Epidemiology, Vol. 28, No. 6, 1999, pp. 1044-1049. doi:10.1093/ije/28.6.1044

[26] H. Adachi, F. C. Goetz, D. R. Jacobs, M. Tsuruta, Y. Hirai, Y. Fujiura, and T. Imaizumi, "The Role of Obesity in the Association of Cardiovascular Risk Factors and Glucose Intolerance in Small Japanese and North American Communities,” Diabetes Research and Clinical Practice, Vol. 41, No. 1, 2000, pp. 41-51. doi:10.1016/S0168-8227(00)00133-9

[27] S. Baba, W. H. Pan, H. Ueshima, H. Ozawa, Y. Komachi, R. Stamler, K. Ruth and J. Stamler, "Blood Pressure Levels, Related Factors, and Hypertension Control Status of Japanese and Americans," Journal of Human Hypertension, Vol. 5, No. 4, 1991, pp. 317-327.

[28] M. C. Fiore, T. E. Novotny, J. P. Pierce, E. J. Hatziandreu, K. M. Patel and R. M. Davis, "Trends in Cigarette Smoking in the United States: The Changing Influence of Sex and Race," The Journal of the American Medical Association, Vol. 261, No. 1, 1989, pp. 49-55. doi:10.1001/jama.261.1.49

[29] G. H. Tofler, P. H. Stone, M. Maclure, E. Edelman, V. G. Davis, T. Robertson, E. M. Antman, J. E. Muller and the MILIS Study Group, "Analysis of Possible Triggers of Acute Myocardial Infarction (The MILIS Study),” American Journal of Cardiology, Vol. 66, No. 1, 1990, pp. 22 27. doi:10.1016/0002-9149(90)90729-K

[30] J. A. Berlin and G. A. Colditz, "A Meta-Analysis of Physical Activity in the Prevention of Coronary Heart Disease," American Journal of Epidemiology, Vol. 132, No. 4, 1990, pp. 612-628.

[31] N. D. Ernst, C. T. Sempos, R. R. Briefel and M. B. Clark, "Consistency between US Dietary Fat Intake and Serum Total Cholesterol Concentrations: The National Health and Nutritional Examination Surveys," The American Journal of Clinical Nutrition, Vol. 66, Supple. 4, 1997, pp. 965S-972S.

[32] H. Iso, S. Sato, A. R. Folsom, T. Shimamoto, A. Terao, R. G. Munger, A. Kitamura, M. Konishi, M. Iida and Y. Komachi, "Serum Fatty Acids and Fish Intake in Rural Japanese, Urban Japanese, Japanese American, and Caucasian American Men,” International Journal of Epidemiology, Vol. 18, No. 2, 1989, pp.374-381. doi:10.1093/ije/18.2.374

[33] R. M. Krauss, R. J. Deckelbaum, N. Ernst, E. Fisher, B. V. Howard, R. H. Knopp, T. Kotchen, A. H. Lichtenstein, H. C. McGill, T. A. Pearson, T. E. Prewitt, N. J. Stone, L. V. Horn and R. Weinberg, "Dietary Guidelines for Healthy American Adults: A Statement for Health Professionals from the Nutrition Committee, American Heart Associa- 
tion,” Circulation, Vol. 94, No. 7, 1996, pp.1795-1800.

[34] A. Ascherio, E. B. Rimm, M. J. Stamper, E. L. Giovannucci and W. C. Willett, "Dietary Intake of Marine n-3 Fatty Acids, Fish Intake, and the Risk of Coronary Disease among Men,” The New England Journal of Medicine, Vol. 332, No. 15, 1995, pp. 979-982. doi:10.1056/NEJM199504133321501

[35] S. Ishikawa, Ed., "The National Nutrition Survey: The
Ministry of Welfare and Labor,” Daiichi Publishing Co., Ltd., Japan, 1999 (in Japanese).

[36] A. Hino, H. Adachi, K. Toyomasu, N. Yoshida, M. Enomoto, A. Hiratsuka, Y. Hirai, A. Satoh and T. Imaizumi, "Very Long Chain N-3 Fatty Acids Intake and Carotid Atherosclerosis: An Epidemiological Study Evaluated by Ultrasonography,” Atherosclerosis, Vol. 176, No. 1, 2004, pp. 145-149. doi:10.1016/j.atherosclerosis.2004.04.020 